\title{
How Many Screws Are Needed for Reliable Stability of Extra-articular Nonosteoporotic Distal Radius Fractures Fixed with Volar Locking Plates?
}

\author{
Hyoung-Seok Jung, MD, Han Sol Jung, MD, Suk-Ho Baek, MD, Jae Sung Lee, MD \\ Department of Orthopedic Surgery, Chung-Ang University Hospital, Seoul, Korea
}

\begin{abstract}
Background: We hypothesized that volar locking pate fixation using a minimum number of screws-four in the distal row and two in the shaft of the plate-will provide sufficient stability for unstable extra-articular fractures of the distal radius. We aimed to compare the biomechanical properties of different numbers and locations of screws in volar locking plate fixation and describe the clinical and radiological outcome of plate fixation using a minimum number of screws for distal radius fractures.

Methods: We divided 48 artificial radius fracture bones into four groups (group A-D) based on the number and location of screws used for fixation with volar locking plates. The artificial bone models were subjected to axial compression and volar bending load with a force of $250 \mathrm{~N}$ and $80 \mathrm{~N}$, respectively, for 1,000 cycles at a frequency of $1 \mathrm{~Hz}$. We also retrospectively reviewed 42 patients with unstable, extra-articular, distal radius fractures who were treated with volar locking plate fixation using a minimum number of screws.
\end{abstract}

Results: Group A (seven distal screws and three proximal screws) had the highest mean stiffness: $303.7 \mathrm{~N} / \mathrm{mm}$ under axial compression and $61.1 \mathrm{~N} / \mathrm{mm}$ under volar bending. Compared with group $A$, group $D$ (four screws in the distal part and two screws in the shaft) showed significantly lower stiffness; therefore, group D was considered inferior in terms of stability. However, in the fatigue test, neither deformation of the metal plate nor detachment or breakage of the metal screws was observed in all groups. In the clinical study, all fractures united without displacement and satisfactory clinical outcome was obtained.

Conclusions: In the dorsally comminuted, extra-articular, nonosteoporotic distal radius fractures, the minimum number of screws - four in the distal row and two in the shaft-in volar locking plate fixation can provide sufficient stability. Further biomechanical studies involving osteoporotic bone will be necessary to confirm the results because volar plate fixation is most commonly used in patients with osteoporosis.

Keywords: Radius fractures, Palmar plate, Bone screw

Volar locking plate fixation has become increasingly popular in the treatment of distal radius fractures. It provides sufficient mechanical stability for patients with poor bone quality due to osteoporosis, reduces tendon irritation, and

Received March 26, 2019; Accepted July 1, 2019

Correspondence to: Jae Sung Lee, MD

Department of Orthropedic Surgery, Chung-Ang University Hospital, 102 Heukseok-ro, Dongjak-gu, Seoul 06973, Korea

Tel: +82-2-6299-3105, Fax: +82-2-793-6634

E-mail: boneman@cau.ac.kr can be performed on a relatively flat and slightly concave surface. ${ }^{1-3)}$ In addition, it enables biomechanically firm fixation, which allows early joint motion. ${ }^{1,4-6)}$ In recently developed volar locking plate systems, the plate is designed for distal screws to have an evenly distributed insertion angle and to be inserted into the subchondral bone, providing additional fixation force and decreasing loss of reduction secondary to screw toggling.

Volar locking plate fixation is often performed with four to nine distal locking screws. Although additional screws can be used to ensure firm fixation, the use of extra 
Jung et al. Volar Locking Plating for Distal Radius Fractures

Clinics in Orthopedic Surgery • Vol. 12, No. 1, $2020 \bullet$ www.ecios.org

screws can be associated with high costs and increased risk of complications such as joint and tendon irritation. ${ }^{7}$ Therefore, biomechanical research is necessary to establish the appropriate number of screws needed to ensure reliable stability after a distal radius fracture. There are many biomechanical studies on the volar locking plate fixation of distal radius fractures. Willis et al. ${ }^{8)}$ compared four volar plates and one dorsal plate in a dorsally communited extra-articular distal radius fracture model (Sawbone model). They concluded that the locking system is stiffer than the nonlocking plate. Other studies investigating the number and location of screws for volar locking plate fixation demonstrated that placing four screws in the distal fragment and at least two screws in the distal row confers reliable stability in a model of distal radius fractures. ${ }^{2,9)}$ However, all these previous studies focused on the fixation of the distal fragment. Although three bicortical screws were commonly used for the proximal fragment in previous biomechanical studies, the question of how many screws are necessary for the proximal fragment has not been answered sufficiently. If the number of screws used on the proximal fragment can be reduced, a short volar locking plate can be used, which will prevent an unnecessary incision for screw fixation.

In this study, we aimed to evaluate the effect of location and number of screws on the fixation stability of volar locking plate fixation and describe the clinical and radiological outcomes of volar locking plate fixation using a minimum number of screws for distal radius fractures.

\section{METHODS}

The design and protocol of this retrospective study were approved by the Institutional Review Board at ChungAng University Hospital (IRB No. 1801-007-16135) and informed consent was waived.

\section{Biomechanical Analysis}

For biomechanical analysis of locking plate fixation, we performed cycling testing with axial compression and volar bending load. A preliminary power analysis showed that a sample size of six per group was needed to obtain an alpha of 0.05 and a power of 0.8. A 48 Sawbone forearms, the fourth generation composite model (Sawbones Worldwide [Pacific Research Laboratories], Vashon Island, WA, USA), were selected for the biomechanical study of dorsally comminuted, extra-articular, distal radius fractures fixed with volar locking plates. Half of the 48 Sawbones (n $=24$ ) were used for the volar bending test and the other half $(\mathrm{n}=24)$ were used for the axial compression test. The distal radius fracture models were designed to have an unstable, wedge-shaped fracture, an 8-mm fracture gap, and a $1-\mathrm{cm}$ space from the distal end on the dorsal side. The Arix Volar Distal Radius Locking Plate (JEIL Medical, Seoul, Korea) made of standard titanium was used: it has a total of seven holes in two rows in the distal part (four holes in the distal-most row and three in the proximal row) and three holes in the shaft.

The 48 synthetic radius fracture bones were divided into four groups by location and number of screw fixation: group A was stabilized with screw insertion in seven holes in the distal part and three holes in the shaft; group B, sev-
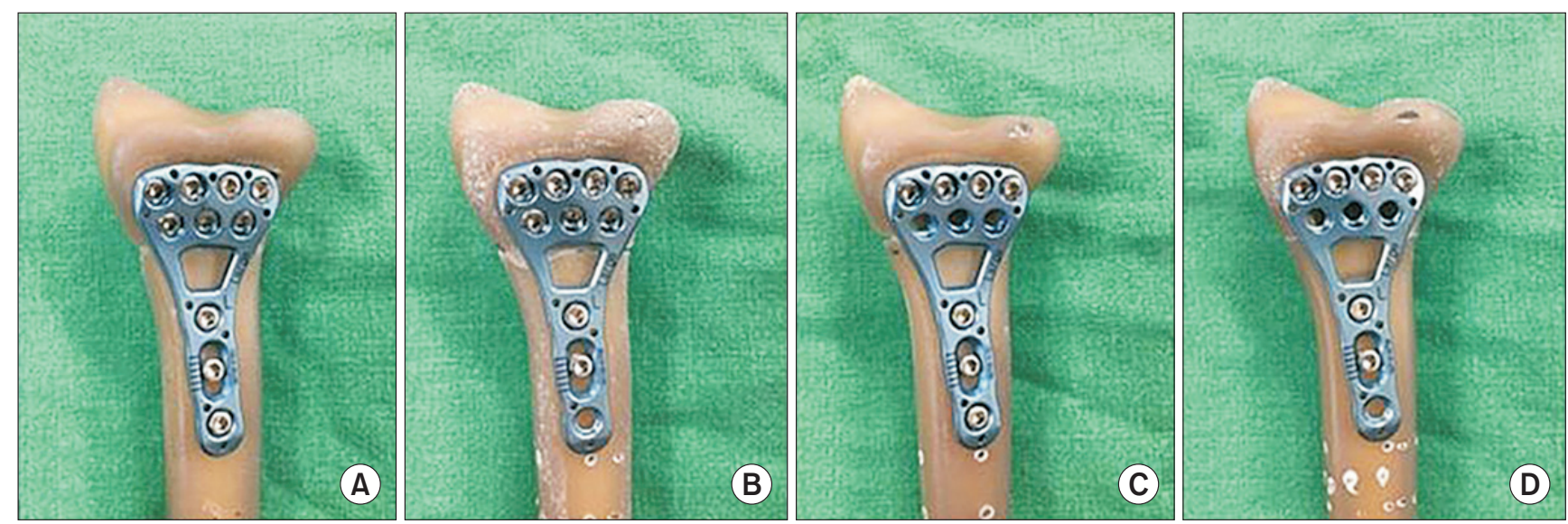

Fig. 1. Four different screw configurations in the distal area and shaft of the radius fracture models. (A) Locking screws were placed in all holes in both rows and in the three holes of the shaft. (B) Locking screws were placed in all holes in both rows and in the two holes of the shaft. (C) Locking screws were placed in all holes of the distal row and in the three holes of the shaft. (D) Locking screws were placed in all holes of the distal row and in the two holes of the shaft. 
Jung et al. Volar Locking Plating for Distal Radius Fractures

Clinics in Orthopedic Surgery • Vol. 12, No. 1, $2020 \bullet$ www.ecios.org

en holes in the distal part and two holes in the shaft; group $\mathrm{C}$, four holes in the distal-most part and three holes in the shaft; and group $\mathrm{D}$, four holes in the distal-most part and two holes in the shaft (Fig. 1). The length of the distal locking screw was $16 \mathrm{~mm}$ and that of the screw in the shaft was $18 \mathrm{~mm}$. The $16-\mathrm{mm}$ distal locking screws did not penetrate the dorsal cortical bone but fixed more than $75 \%$ of the bone thickness, while the screws in the shaft were inserted to penetrate the dorsal cortical bone to ensure firm fixation. All distal locking screws used in this study were fixed-angle screws. In the shaft, a cortical screw was used in the middle hole of the plate. After fixation, fatigue tests were performed bidirectionally in the total 48 synthetic radius bones six in each group. Cycling testing with axial compression and volar bending load was performed by using an ElectroPuls E3000 Linear-Torsion testing machine (Instron, Norwood, MA, USA). The axial compression fatigue test was conducted in 24 synthetic radius bones with a force of $250 \mathrm{~N}$ in the direction of axial compression for 1,000 cycles at a frequency of $1 \mathrm{~Hz}$. The shear force fatigue test was performed in the other 24 synthetic radius bones with a force of $80 \mathrm{~N}$ from the volar side to the dorsal side for 1,000 cycles at a frequency of $1 \mathrm{~Hz}$ (Fig. 2). ${ }^{9}$ )

In all cycling tests, the load was applied to the radius models at the same site and from the same height. The compression force was set at $250 \mathrm{~N}$ on the basis of previous studies suggesting that compressive forces created by light active motion of the wrist do not exceed $100 \mathrm{~N}$ and combined forces of motion of the wrist and digits do not exceed $250 \mathrm{~N}^{10-14)}$ Load and displacement data were recorded and respective curves were plotted. Stiffness was defined as a tangent line of the load-displacement curve. Failure was defined as deformation of the metal plate or detachment, breakage of the metal screw, or more than 2-mm difference in the fracture gap. ${ }^{2)}$

\section{Clinical Study}

We retrospectively reviewed 69 patients with distal radius fractures treated with volar locking plate fixation using the minimum number of screws at our institution. All fractures were classified by $\mathrm{AO}$ classification and only $\mathrm{AO}$ type 23-A2 and 23-A3 fracture patterns requiring surgical fixation were included in the study. Exclusion criteria were open fracture, concomitant ipsilateral upper limb injury, neurovascular injury, and previous injuries on the affected side. Study enrollment was also limited to patients above 18 years of age. Operations were performed by a single surgeon (JSL). A $2.5-\mathrm{cm}$ small skin incision was made, and the fracture was exposed by a volar Henry approach. Open reduction and volar radius locking plating (JEIL Medical) were performed. Plates were fixed with four screws in the distal row and two screws in the shaft (as in model of group D described in the biomechanical study). Distal locking screws did not penetrate the dorsal cortical bone, while the screws in the shaft passed through the dorsal cortical bone. All patients had a removable splint for 4 weeks and were allowed early movement of their wrist and fingers. Patients returned to the clinic for evaluation at 2 , 6 , and 12 weeks, 6 months, and 1 year after surgery. Functional outcome was assessed by the wrist range of motion, grip strength, and quick Disabilities of the Arm, Shoulder, and Hand (DASH). Radiography was performed at each
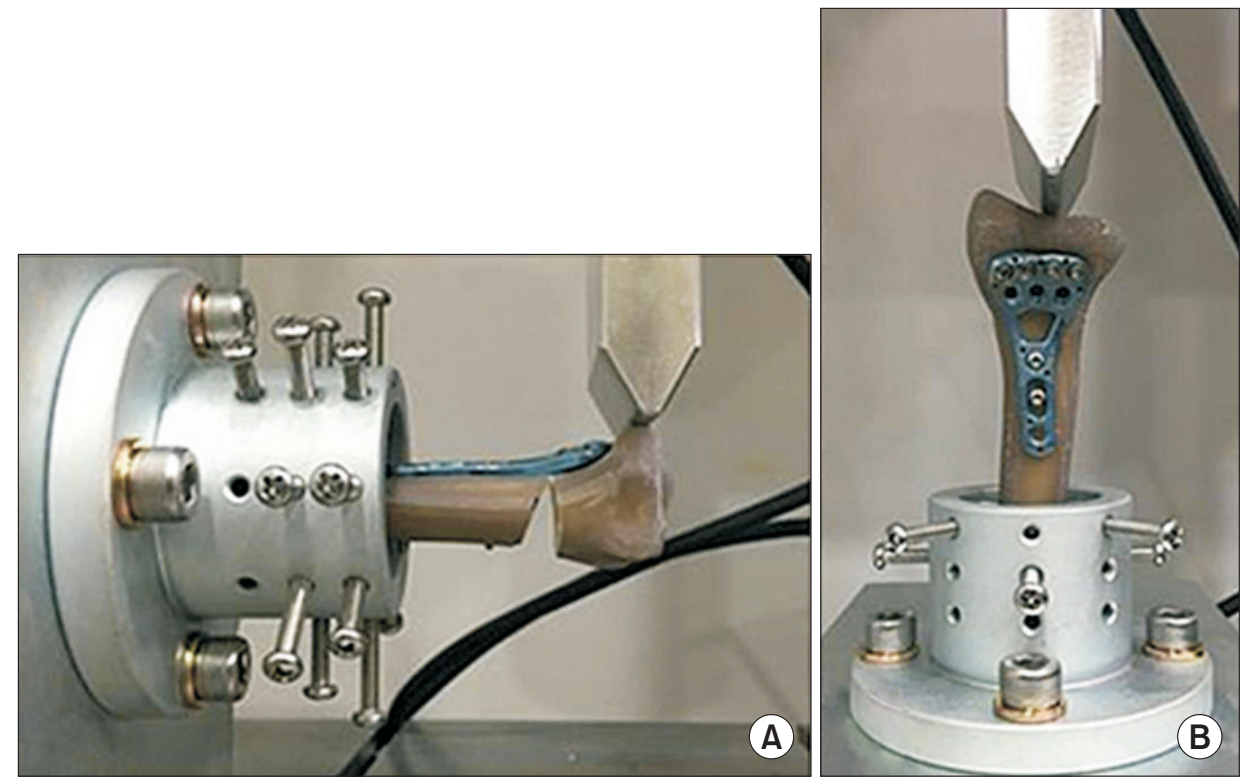

Fig. 2. Axial compression and volar bending tests. Each specimen was placed in the machine and tested under volar bending (A) and axial compression (B). 
follow-up visit to evaluate loss of reduction; radial inclination, length, and volar tilt were assessed at the final followup. All images were evaluated by a hand surgeon (HSJ) not involved in the patient care.

\section{Statistical Analysis}

Respective stiffness under axial compression and volar bending load was set as a dependent variable. The normal distribution of the resulting values was confirmed with Kolmogorov-Smirnov test. One-way analysis of variance and post-hoc analysis were performed to evaluate statistical significance. A statistically significant difference was defined as a $p$-value $<0.05$.

\section{RESULTS}

During 1,000 cycles of the axial compression and volar bending fatigue tests, the change in fracture gap was less than $2 \mathrm{~mm}$ in all groups. Stiffness showed unstable values during the first 100 cycles in all groups and then stabilized thereafter. Thus, we considered the stiffness value after 100 cycles a meaningful value. After the fatigue test, neither

\begin{tabular}{|c|c|}
\hline Group & $p$-value for axial comparison \\
\hline A vs. B & 0.562 \\
\hline A vs. C & 0.005 \\
\hline A vs. D & 0.005 \\
\hline B vs. C & 0.173 \\
\hline B vs. D & 0.178 \\
\hline C vs. D & 1.000 \\
\hline
\end{tabular}

\begin{tabular}{|c|c|}
\hline Groups compared & $p$-value for volar bending \\
\hline Avs. B & 0.996 \\
\hline A vs. C & 0.208 \\
\hline Avs. D & 0.018 \\
\hline B vs. C & 0.846 \\
\hline B vs. D & 0.288 \\
\hline C vs. D & 0.561 \\
\hline
\end{tabular}

deformation of the metal plates nor detachment or breakage of the metal screws was observed in all groups.

On the axial compression fatigue test, the mean value of stiffness was $303.7 \mathrm{~N} / \mathrm{mm}$ in group A, $262.5 \mathrm{~N} / \mathrm{mm}$ in group $\mathrm{B}, 189.1 \mathrm{~N} / \mathrm{mm}$ in group $\mathrm{C}$, and $165.9 \mathrm{~N} / \mathrm{mm}$ in group $\mathrm{D}$. There was no statistically significant difference in mean stiffness between group A and group B $(p=0.562)$; however, group A showed a higher mean stiffness than groups $\mathrm{C}$ and $\mathrm{D}(p=0.005, p=0.005$, respectively). There was no significant difference in mean stiffness between the other groups and no specimen failed before reaching the defined load (Table 1).

On the volar bending fatigue test, the mean stiffness was $61.1 \mathrm{~N} / \mathrm{mm}$ in group A, $58.1 \mathrm{~N} / \mathrm{mm}$ in group B, 51.5 $\mathrm{N} / \mathrm{mm}$ in group $\mathrm{C}$, and $48.8 \mathrm{~N} / \mathrm{mm}$ in group $\mathrm{D}$. The mean stiffness of group A was significantly different from that of group $\mathrm{D}(p=0.018)$, but there was no statistically significant difference in stiffness between the other groups, and no specimen failed before reaching the defined load (Table 2). In the clinical study, there was no loss of reduction and nonunion throughout the follow-up. Of the 69 patients with volar plate fixation, 27 patients were excluded from the study: 11 patients with concomitant ipsilateral upper limb injury, three patients with an open distal radius fracture, and 13 patients who were lost to follow-up. Thus, 42 patients (16 men and 26 women) were included in the final analysis. The mean follow-up period was 13.6 months and the mean age was 62.9 years (Table 3 ). The average flexion-extension arc of the wrist was $125.5^{\circ}$ (range, $100^{\circ}$ to $152^{\circ}$ ), the mean grip strength was $76 \%$ of that of the uninjured contralateral side, and the mean quick DASH score

\section{Table 3. Patient Demographics}

\begin{tabular}{|l|l|}
\hline Characteristic & Value \\
\hline Age (yr) & $62.9(34-80)$ \\
\hline Sex & $16(38)$ \\
\hline Male & $26(62)$ \\
\hline Female & \\
\hline Side & $20(48)$ \\
\hline Right & $22(52)$ \\
\hline Left & \\
\hline A0 classification & $10(24)$ \\
\hline $23-A 2$ & $32(76)$ \\
\hline $23-A 3$ & \\
\hline
\end{tabular}

Values are presented as mean (range) or number (\%). 
Jung et al. Volar Locking Plating for Distal Radius Fractures

Clinics in Orthopedic Surgery • Vol. 12, No. 1, $2020 \bullet$ www.ecios.org
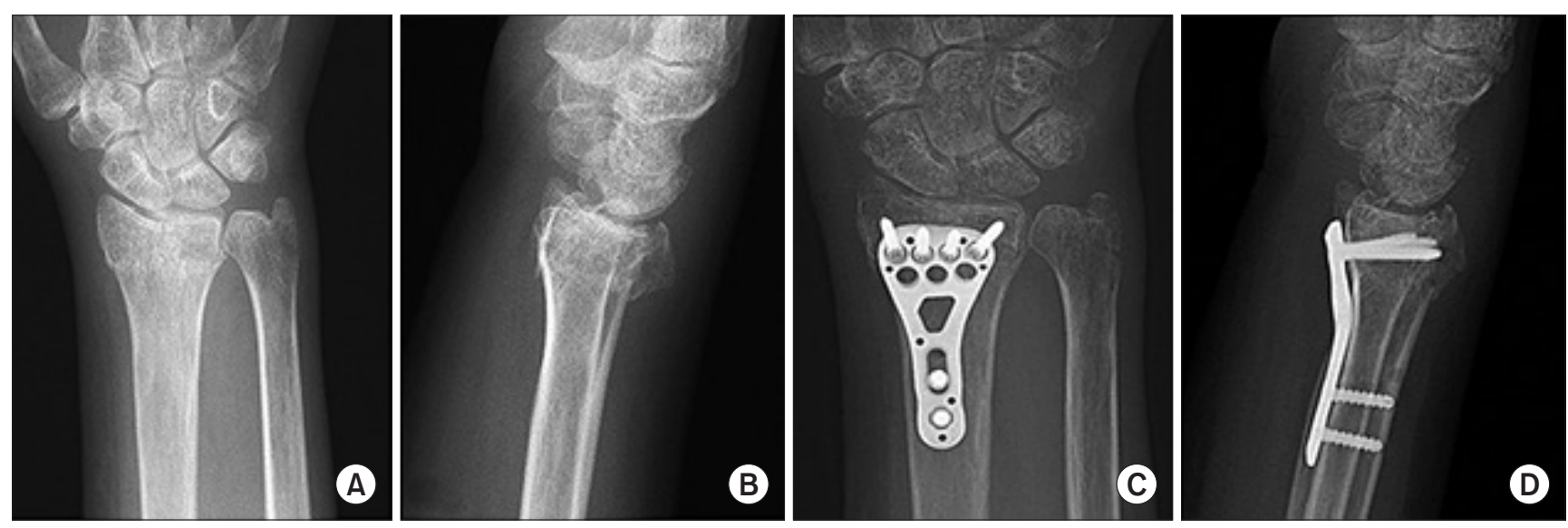

Fig. 3. Preoperative anteroposterior (A) and lateral (B) radiographs of a closed extra-articular distal radius fracture treated with volar locking plate fixation using a minimum number of screws (four in the distal row and two in the proximal shaft). Anteroposterior (C) and lateral (D) radiographs at 12 months after surgery.

was 8.2 (range, 0 to 22.7). At the final follow-up, the mean radial inclination was $21.1^{\circ}$ (range, $17.2^{\circ}$ to $26.9^{\circ}$ ), the mean radial height was $10.1 \mathrm{~mm}$ (range, 7.2 to $13.3 \mathrm{~mm}$ ), and the mean volar tilt was $10.7^{\circ}$ (range, $8.4^{\circ}$ to $16.2^{\circ}$ ) (Fig. 3). There were no significant complications including malunion, tendon irritation or rupture, and neurovascular injury.

\section{DISCUSSION}

The purpose of this biomechanical analysis was to compare the stability of four different models of distal radius fractures according to the location and number of screws used for volar locking plate fixation. The maximum stability was found in group A in which seven distal screws and three proximal screws were used. In comparison, group D, in which four screws in the distal part and two screws in the shaft were inserted, showed significantly lower stiffness than group A; therefore, group D was considered inferior in terms of stability. However, after the fatigue test, neither deformation of the metal plate nor detachment or breakage of the metal screws was observed in any of the models. Therefore, considering that the compression tests were performed with a force of $250 \mathrm{~N}$, which is greater than the level of combined forces of active motion in the wrist and digits, we concluded all models would withstand average daily movement of the wrist.

Theoretically, as the number of distal locking screws used increases, more bone fragments can be fixed, and fixation stiffness will increase accordingly. However, the use of extra locking screws leads to higher expenses (approximately $\$ 60$ to $\$ 100$ per screw) and increased risk of screw-related complications. ${ }^{7,15)}$ Limiting costs and reducing screw-related complications are also important goals of fracture fixation. Drobetz et al. ${ }^{16)}$ reported that the stiffness of models with two-row volar locking plates was not significantly higher than that of the models with single-row volar locking plates. Mehling et al. ${ }^{9)}$ conducted a comparison study similar to the present study by altering the number and location of distal locking screws. They reported that all groups had sufficient stiffness to withstand postoperative rehabilitation, except for the group in which the three locking screws were inserted in the proximal row. ${ }^{9)}$ They demonstrated that inserting screws in all available holes in the distal fragment offers the highest stability and using only three screws in the proximal row creates an unstable situation. Moss et al. ${ }^{2)}$ compared the stability of the group using four distal locking screws and the group using seven distal locking screws. There was no significant difference in stiffness between the two groups, and no fixation failure occurred. All these previous studies and our study show that stable fixation can be ensured by using four distal locking screws. However, to our knowledge, there have been no biomechanical studies in the literature on the the number of minimum screws needed in the proximal part .

In our study, there was no significant difference in mean stiffness between groups A and B. Similarly, there was no significant difference in mean stiffness between groups $\mathrm{C}$ and $\mathrm{D}$. Each group varied only in the number of screws used in the shaft. Therefore, on the basis of previous studies and the present study, we believe that fixation with all screws of the distal row in the distal part and two screws in the proximal part of the plate will provide sufficient fixation strength for unstable, extra-articular, distal radius fractures. 
Jung et al. Volar Locking Plating for Distal Radius Fractures

Clinics in Orthopedic Surgery • Vol. 12, No. 1, $2020 \bullet$ www.ecios.org

In clinical practice, it has been reported that there is no significant difference in the radiological results according to the number of screws used in volar locking plate fixation. Neuhaus et al. ${ }^{7)}$ reported that there was no difference in the degree of secondary reduction loss between the one-row volar locking plate group and the two-row volar locking plate group. They also reported that these results were independent of patients' age and gender, $\mathrm{AO}$ fracture classification, degree of posterior comminuted fracture, presence or absence of ulnar fracture, and mechanism of injury. Choi et al. ${ }^{17)}$ reported there was no significant difference in radiological outcomes between the group using fewer than five distal locking screws in the volar locking plate and the group using more than six distal locking screws in the volar locking plate. Although we did not compare the radiographic results according to the number and location of screws, satisfactory radiological and clinical outcome was obtained by using a minimum number of screws. Furthermore, the skin incision was minimized by avoiding screw fixation at the most proximal hole in the shaft.

This study has several limitations. First, since the Sawbone models were used instead of human bone in the biomechanical analysis, we could not determine the reproducibility of biomechanical evaluation results in a clinical setting. To overcome this, we performed the retrospective study using a minimum number of screws with the plate and obtained satisfactory clinical outcome. Second, we did not evaluate the factors that can affect loss of fracture reduction, such as the position of the volar plate, type of the volar plate, and length of the distal locking screw. Fur- thermore, the impact of bone mineral density, which also contributes to loss of reduction, was not considered in the study. Therefore, further biomechanical studies involving only osteoporotic bone will be necessary to confirm our results. Third, although the tests were performed with a force of $250 \mathrm{~N}$, it is undetermined whether the level of force in vivo contributed to the difference in stiffness between the groups. However, many previous studies used $250 \mathrm{~N}$ for the model of a distal radius fracture, and we demonstrated that no specimen failed with this value. ${ }^{2,8,9)}$ Finally, we did not consider the ultimate tensile strength as a significant parameter in fixation stability. However, more than $700 \mathrm{~N}$ load was needed to deform Sawbone models in the preliminary study using cycling testing in all groups, which was not feasible clinically and thus tensile strength was not measured in the clinical study.

In conclusion, our study shows that using the minimum number of screws-four in the distal row and two in the shaft-in volar locking plate fixation provides sufficient stability for the dorsally comminuted, extra-articular, non-osteoporotic distal radius fractures, although allscrew fixation provides greater stability. Further biomechanical studies involving osteoporotic bone will be necessary because volar plates are most commonly used in osteoporotic patients.

\section{CONFLICT OF INTEREST}

No potential conflict of interest relevant to this article was reported.

\section{REFERENCES}

1. Mackenney PJ, McQueen MM, Elton R. Prediction of instability in distal radial fractures. J Bone Joint Surg Am. 2006;88(9):1944-51.

2. Moss DP, Means KR Jr, Parks BG, Forthman CL. A biomechanical comparison of volar locked plating of intraarticular distal radius fractures: use of 4 versus 7 screws for distal fixation. J Hand Surg Am. 2011;36(12):1907-11.

3. Souer JS, Lozano-Calderon SA, Ring D. Predictors of wrist function and health status after operative treatment of fractures of the distal radius. J Hand Surg Am. 2008;33(2):15763.

4. Arora R, Lutz M, Hennerbichler A, Krappinger D, Espen D, Gabl M. Complications following internal fixation of unstable distal radius fracture with a palmar locking-plate. J Orthop Trauma. 2007;21(5):316-22.
5. Lucado AM, Li Z. Static progressive splinting to improve wrist stiffness after distal radius fracture: a prospective, case series study. Physiother Theory Pract. 2009;25(4):297-309.

6. Soong M, van Leerdam R, Guitton TG, Got C, Katarincic J, Ring D. Fracture of the distal radius: risk factors for complications after locked volar plate fixation. J Hand Surg Am. 2011;36(1):3-9.

7. Neuhaus V, Badri O, Ferree S, Bot AG, Ring DC, Mudgal CS. Radiographic alignment of unstable distal radius fractures fixed with 1 or 2 rows of screws in volar locking plates. J Hand Surg Am. 2013;38(2):297-301.

8. Willis AA, Kutsumi K, Zobitz ME, Cooney WP 3rd. Internal fixation of dorsally displaced fractures of the distal part of the radius: a biomechanical analysis of volar plate fracture stability. J Bone Joint Surg Am. 2006;88(11):2411-7. 
9. Mehling I, Muller LP, Delinsky K, Mehler D, Burkhart KJ, Rommens PM. Number and locations of screw fixation for volar fixed-angle plating of distal radius fractures: biomechanical study. J Hand Surg Am. 2010;35(6):885-91.

10. Chao EY, Opgrande JD, Axmear FE. Three-dimensional force analysis of finger joints in selected isometric hand functions. J Biomech. 1976;9(6):387-96.

11. Mochizuki Y, Ikuta Y, Ikeda A, Yoshii I. Biomechanics of the wrist joint. In: Poitout DG, ed. Biomechanics and biomaterials in orthopedics. London: Springer; 2004. 397-402.

12. Peine R, Rikli DA, Hoffmann R, Duda G, Regazzoni P. Comparison of three different plating techniques for the dorsum of the distal radius: a biomechanical study. J Hand Surg Am. 2000;25(1):29-33.

13. Wolfe SW, Swigart CR, Grauer J, Slade JF 3rd, Panjabi MM. Augmented external fixation of distal radius fractures: a biomechanical analysis. J Hand Surg Am. 1998;23(1):127-34.
14. Yetkinler DN, Ladd AL, Poser RD, Constantz BR, Carter D. Biomechanical evaluation of fixation of intra-articular fractures of the distal part of the radius in cadavera: Kirschner wires compared with calcium-phosphate bone cement. J Bone Joint Surg Am. 1999;81(3):391-9.

15. Maschke SD, Evans PJ, Schub D, Drake R, Lawton JN. Radiographic evaluation of dorsal screw penetration after volar fixed-angle plating of the distal radius: a cadaveric study. Hand (N Y). 2007;2(3):144-50.

16. Drobetz $\mathrm{H}$, Weninger $\mathrm{P}$, Grant $\mathrm{C}$, et al. More is not necessarily better: a biomechanical study on distal screw numbers in volar locking distal radius plates. Injury. 2013;44(4):535-9.

17. Choi HC, Lee JY, Jung JY, Park IJ, Chung YG. Radiologic results in accordance with the number of distal locking screws in volar plate fixation for distal radius fractures. J Korean Soc Surg Hand. 2014;19(3):124-9. 